\title{
Dimensionamentos curriculares de enfoque CTS no ensino de ciências na educação básica
}

Curriculum sizing of STS approach in teaching science in basic education

Guilherme Schwan (iD http://orcid.org/0000-0002-2859-3579

Universidade Federal da Fronteira Sul

guilhermeschwan@gmail.com

Rosemar Ayres dos Santos (Di) http://orcid.org/0000-0002-1068-2872

Universidade Federal da Fronteira Sul

roseayres07@gmail.com

\section{Resumo}

Com a rápida evolução da Ciência-Tecnologia há necessidade de constantes inovações, também, na forma de ensinar, tanto com metodologias diferenciadas quanto a um olhar mais amplo para novas possibilidades de configurações curriculares. Nessa perspectiva, esse trabalho apresenta uma revisão bibliográfica de cunho qualitativo, a qual teve como corpus de análise teses e dissertações do repositório do Instituto Brasileiro de Informação em Ciência e Tecnologia. Investigamos: como currículos de viés CTS estão sendo abordados no ensino de ciências na Educação Básica? E, a partir desses, de que forma o conhecimento acerca de questões científico-tecnológicas contribuem no desenvolvimento crítico do estudante? Objetivamos identificar o enfoque dado ao currículo de viés CTS no ensino de ciências, refletindo sobre as diferentes formas de ensinar e seus resultados, e, a partir desse, compreender como esse currículo é abordado e de qual maneira se busca despertar o olhar crítico dos estudantes. Metodologicamente, utilizamos a Análise Textual Discursiva, que é estruturada em três etapas: unitarização, categorização e comunicação. A partir da análise, apresentamos os resultados em duas categorias: a) currículos com enfoque CTS no ensino de ciência e; b) pensar crítico de estudantes junto aos objetivos da educação CTS. Contribuindo com uma maior articulação e elucidação para que haja maiores problematizações críticas a respeito de currículos, para que se produzam configurações curriculares que visem à compreensão das relações CTS na Educação Básica, uma reorganização curricular que perpasse pelos objetivos do enfoque CTS.

Palavras-chave: Currículo. Ensino de Ciências. Ciência e Tecnologia. Educação Básica. 


\begin{abstract}
With the fast evolution of Science-Technology, there is the need of constant innovation, also, the teaching way, as in different methodology as with a wider look at new possibilities of curricular settings. In this perspective, the current work presents a bibliographic review of qualitative imprint, which has as analysis some corpus repository theses and dissertations of the Brazilian Institute of Information in Science and Technology. We investigate: how do bias curriculum STS is being approached in teaching Science in Basic Education? Moreover, from these, in which way do the knowledge about scientific-technology matter contribute to student's critical knowledge? Our objective is to identify the focus given to bias curriculum STS in teaching Science, reflecting about different ways of teaching and its results, and, from this understand how this curriculum is approached and in which way it seeks to awaken it to student's critical look. Methodologically, we used Discursive Textual Analysis that is structured in three steps: unitization, categorization and communication. From the analysis, we presented the results in two steps: a) curriculum focusing on STS in teaching Science and; b) student's critical thinking alongside STS educational purposes. Contributing to a bigger articulation and elucidation so there is bigger critical problematization regarding curriculum, in order to produce curricular settings aiming STS relationship understanding in Basic Education, a curricular reorganization that runs through STS focus objectives.
\end{abstract}

Keywords: Curriculum. Teaching Science. Science and Technology. Basic Education.

\title{
Introdução
}

Com a rápida evolução da Ciência-Tecnologia $(\mathrm{CT})$ há necessidade de constantes inovações, também, na forma de ensinar, tanto com metodologias diferenciadas quanto a um olhar mais amplo para novas possibilidades de configurações curriculares. Para tanto, seria necessário reformular e adotar medidas que contribuam para a mudança da atual situação de um currículo tradicional e definido a priori, para o desenvolvimento de propostas curriculares articuladas aos objetivos Ciência-Tecnologia-Sociedade (CTS), estimulando a criticidade e participação dos estudantes na Educação Básica.

A crítica recorre a currículos denominados tradicionais definidos sem participação efetiva dos professores, estes, agentes essenciais no contexto escolar. Portanto, a partir de olhares práticos, que colaboram para maior poder decisório e participação deles na construção curricular, ao instigar e contribuir com reflexões críticas a partir deste currículo pré-determinado, utilizando estas reflexões para produzir um currículo escrito que realmente reflita vivências sociais do contexto em que professores e estudantes estão inseridos, sendo para isso necessário diminuir a "dicotomia" referida por Goodson (1991), de currículo escrito, pré-determinado sem conexões com a prática, porém, sem esquecer as construções históricas envoltas na formulação do currículo escrito e apenas enfocar no "currículo como prática", oferecendo a opção de localizarmos os problemas contemporâneos a partir de olhares históricos.

O ponto é que o potencial para uma relação estreita ou, no outro extremo, a falta de relação entre teoria e prática ou entre a escrita de currículo e currículo ativo depende da natureza da construção proativa de abordagens 
e teorias curriculares, bem como a realização interativa do currículo na sala de aula. (GOODSON, 1991, p.13).

Pois, "A prática é uma existência real, que uma teorização deve explicar esclarecer, tarefa difícil quando se trata de práticas diferentes e teorias diferentes cabe ao currículo conectar esses diferentes olhares". (SACRISTÁN, 2000, p. 21). No entanto, currículos escritos pré-determinados, sem conexões com o contexto social escolar, ainda determinam o curso metodológico de professores em suas disciplinas. Com intuito de contribuir na reformulação de currículos tradicionais, passam a existir movimentos que buscam maior contextualização curricular, e nos tem revelado o aumento de configurações alicerçadas em Paulo Freire, em uma cultura de diálogo, participação e problematização do contexto. Considerando que "[...] No processo de problematização, o educando tem de confrontar-se com situações de sua vivência. [...]" (SANTOS, 2016, p. 64). Junto a estes, estão ligados os pressupostos do movimento Ciência-Tecnologia-Sociedade (CTS), que, segundo Vaz; Fagundes e Pinheiro 2009, na educação, esse movimento surgiu, por volta de 1970, com o "intuito da necessidade que a sociedade deveria conhecer seus direitos e suas obrigações, de um pensar coletivo, e se tornar um ser de visão crítica, para ter condições de tomar suas decisões e transformar a sociedade onde vive" (p. 108).

Já o movimento mais amplo teve origem em meados do século $X X$, no Hemisfério Norte, principalmente nos países ditos capitalistas, com 0 intuito do desenvolvimento do bem-estar social, contrapondo-se à ideia de que mais Ciência e mais Tecnologia irão, necessariamente, resolver os problemas ambientais, sociais e econômicos. Nesse âmbito, Auler e Delizoicov (2006) destacam que, desse momento em diante, a sociedade passou a possuir um maior controle sobre as ações científico-tecnológicas. Assim, o movimento CTS tem como objetivo central a busca da democratização de processos decisórios envolvendo temas/problemas condicionados pelo desenvolvimento da CT "na sociedade, dos produtos científicotecnológicos, ou seja, busca-se uma participação que atenue seus efeitos negativos, indesejáveis (SANTOS; ROSA; AULER, 2013, p. 18). O surgimento do movimento CTS, em aspectos gerais, é vinculado à contraposição social quanto aos aspectos danosos do desenvolvimento científico tecnológico, já o enfoque CTS neste trabalho é relacionado à educação, principalmente a dimensionamentos curriculares no Ensino de Ciências.

No Brasil, esse movimento teve início na década de oitenta do século $X X$, momento em que a renovação do Ensino de Ciências passou a se orientar tendo por objetivo analisar as implicações sociais do desenvolvimento científico-tecnológico (SANTOS; MORTIMER, 2002). A educação CTS busca na formação de estudantes condições de estabelecerem "laços" na educação, que, segundo Strieder, são pontos-chaves para:

[...] proporcionar aos alunos meios para emitirem julgamentos conscientes sobre problemas da sociedade; proporcionar uma perspectiva mais rica e mais realista sobre a história e a natureza da ciência; tornar a ciência mais acessível e mais atraente a alunos de diferentes capacidades sensibilidades, e preparar os jovens para o papel de cidadãos numa sociedade democrática (STRIEDER, 2008, p. 26).

Portanto, este trabalho se limita à problemática: Como currículos de viés CTS são abordados no ensino de ciências na Educação Básica? De que forma o conhecimento acerca de questões científico-tecnológicas contribui no desenvolvimento crítico do estudante? Tendo como objetivo analisar as pesquisas 
presentes no repositório do Instituto Brasileiro de Informação em Ciência e Tecnologia (IBICT), o enfoque dado ao currículo de viés CTS no ensino de ciências, refletindo sobre as diferentes formas de ensinar e seus resultados e, a partir desse, compreender como esse currículo de viés CTS é abordado e de qual maneira se busca despertar o olhar crítico dos estudantes envolvidos em suas práticas e/ou análises documentais/bibliográficas que tenham como foco a Educação Básica e busquem aproximação com os pressupostos do educador Paulo Freire a referenciais ligados ao movimento CTS.

\title{
Desenvolvimento
}

Este trabalho apresenta uma revisão bibliográfica, de cunho qualitativo (GIL), cuja linha metodológica obedeceu à Análise Textual Discursiva (ATD) (MORAES, 2003; MORAES; GALIAZZI, 2006; MORAES; GALIAZZI, 2013), na qual, a partir de um conjunto de textos, produz-se um novo texto descrevendo e interpretando sentidos e significados destes textos iniciais. Assim, a ATD:

\begin{abstract}
[...] pode ser compreendida como um processo auto-organizado de compreensão de construção em que novos entendimentos emergem de uma sequência recursiva de três componentes: desconstrução dos textos do corpus, a unitarização; estabelecimento de relações entre os elementos unitários, a categorização; o captar do novo emergente em que a nova compreensão é comunicada e validada. (MORAES, 2003, p.192).
\end{abstract}

Tal análise é estruturada em três etapas: Unitarização: fragmentação dos textos elaborados por meio das compreensões dos trabalhos, em que os textos são separados em unidades de significado. Categorização: as unidades de significado são agrupadas segundo suas semelhanças semânticas. Comunicação: elaboraramse textos descritivos e interpretativos (metatextos) acerca das categorias temáticas (MORAES; GALIAZZI, 2006). Na definição e delimitação do corpus de análise, realizamos um levantamento das pesquisas disponíveis na Biblioteca Digital Brasileira de Teses e Dissertações (BDTD), pertencente ao Instituto Brasileiro de Informação em Ciência e Tecnologia (IBICT). Inicialmente, utilizamos como termos de busca: Currículo CTS; Ensino de Ciências. Desta delimitação, obtiveram-se 92 trabalhos entre teses e dissertações (76 dissertações e 16 teses), porém, como tínhamos o objetivo de realizar a pesquisa na Educação Básica, estabelecemos como novos termos na busca: Currículo CTS, CTS na Educação Básica, CTS no Ensino de Ciências como critério de seleção. Obtendo um total, entre teses e dissertações, de 22 pesquisas, disponíveis no repositório até o dia 22 de maio de 2019.

A partir de resultados encontrados, os quais não refletiam apenas práticas efetivas em sala de aula, mas também análises bibliográficas e tendo como foco os objetivos de nossa análise mais centrada no ensino de ciências e qual nível da Educação Básica tal pesquisa abrangia (fundamental ou médio), detivemo-nos nesses, não considerando as práticas e formações voltadas a professores, restando, então, 10 pesquisas efetivamente analisadas e por estarem disponíveis em acesso livre e online. Como todas as pesquisas são dissertações, identificamos os núcleos de sentido como D1, D2, D3....D10, no decorrer do trabalho. São pesquisas encontradas a partir do critério utilizado na seleção do corpus, o que não significa a inexistência de diferentes teses e dissertações que tragam pesquisas nessa mesma 
linha. As questões éticas de pesquisa foram respeitadas, uma vez que foram analisadas pesquisas disponíveis em sites de domínio público.

Seguindo as etapas metodológicas estabelecidas pela ATD, após a etapa de unitarização, identificamos as unidades de significados a partir dos excertos selecionados que atendiam aos nossos objetivos e problema de pesquisa, exemplificadas a seguir.

A) Dimensionamento Curricular - Reformulação - Contexto CTS - Freire - Exame Nacional do Ensino Médio (ENEM).

B) Pensamento Crítico - Educação Científica Tecnológica - Social - Emancipatório - Participativo - Professores.

Desta forma, reunimos tais unidades de significado, surgindo de forma emergente duas categorias que compõem a segunda etapa da ATD (categorização). "Currículos com enfoque CTS no Ensino de Ciência" e "Pensar crítico de estudantes junto aos objetivos da educação CTS". Para serem melhor identificados nos resultados os núcleos de sentido pertencentes ao corpus de análise, terão destaque em itálico. Na delimitação do corpus não houve distinção entre trabalhos de revisões bibliográficas/documentais, para trabalhos de práticas efetivas em sala de aula, utilizando ambas as pesquisas.

Quadro 1- Dissertações encontradas no repositório do Instituto Brasileiro de Informação em Ciência e Tecnologia (IBICT), utilizadas na composição deste trabalho.

\begin{tabular}{|c|c|c|c|c|}
\hline $\mathrm{N}^{\circ}$ & Título & Autor & Ano & Instituição \\
\hline 1 & $\begin{array}{l}\text { EXAME NACIONAL DO ENSINO MÉDIO (ENEM): } \\
\text { ARTICULAÇÕES ENTRE A EDUCAÇÃO CIÊNCIA } \\
\text { TECNOLOGIA E SOCIEDADE E A PROPOSTA } \\
\text { NACIONAL PARA O ENSINO DE QUÍMICA. } \\
\text { (D1) }\end{array}$ & $\begin{array}{l}\text { MASCIO, } \\
\text { Carlos César. }\end{array}$ & 2009 & UFSCar \\
\hline 2 & $\begin{array}{l}\text { O DEBATE SOBRE O AQUECIMENTO GLOBAL } \\
\text { EM SALA DE AULA: O SUJEITO DIALÓGICO E A } \\
\text { RESPONSABILIDADE DO ATO FRENTE A UM } \\
\text { PROBLEMA } \\
\text { CONTROVERSO. } \\
\text { (D2) }\end{array}$ & $\begin{array}{l}\text { BARBOSA, } \\
\text { Luis Gustavo } \\
\text { D'Carlos. }\end{array}$ & 2010 & UFMG \\
\hline 3 & $\begin{array}{l}\text { O EXAME NACIONAL DO ENSINO MÉDIO E A } \\
\text { EDUCAÇÃO QUÍMICA: EM BUSCA DA } \\
\text { CONTEXTUALIZAÇÃO. } \\
\text { (D3) }\end{array}$ & $\begin{array}{l}\text { FERNANDES, } \\
\text { Carolina dos } \\
\text { Santos. }\end{array}$ & 2011 & UFSC \\
\hline 4 & $\begin{array}{l}\text { ABORDAGEM TEMÁTICA E A INTRODUÇÃO DE } \\
\text { CONTEÚDOS DE FÍSICA MODERNA E } \\
\text { CONTEMPORÂNEA NO ENSINO MÉDIO: UMA } \\
\text { PRIMEIRA APROXIMAÇÃO. } \\
\text { (D4) }\end{array}$ & $\begin{array}{l}\text { FIGUEIRA, } \\
\text { Rafael. }\end{array}$ & 2014 & UFSCar \\
\hline 5 & $\begin{array}{l}\text { A CIÊNCIA, TECNOLOGIA E SOCIEDADE (CTS) } \\
\text { COMO UMA PROPOSTA CURRICULAR PARA O } \\
\text { ENSINO MÉDIO POLITÉCNICO NO RIO GRANDE } \\
\text { DO SUL. } \\
\text { (D5) }\end{array}$ & $\begin{array}{l}\text { PEREIRA, } \\
\text { Daniel } \\
\text { Souza. }\end{array}$ & 2016 & UFPEL \\
\hline 6 & $\begin{array}{l}\text { A FISICA NO ENEM DOS ANOS DE } 2008 \text { E } 2009 \\
\text { SOB O OLHAR DO MOVIMENTO: CIÊNCIA, } \\
\text { TECNOLOGIA E SOCIEDADE. } \\
\text { (D6) }\end{array}$ & $\begin{array}{l}\text { SILVA, Márcio } \\
\text { Lima da. }\end{array}$ & 2016 & UNINOVE \\
\hline
\end{tabular}




\begin{tabular}{|c|c|c|c|c|}
\hline 7 & 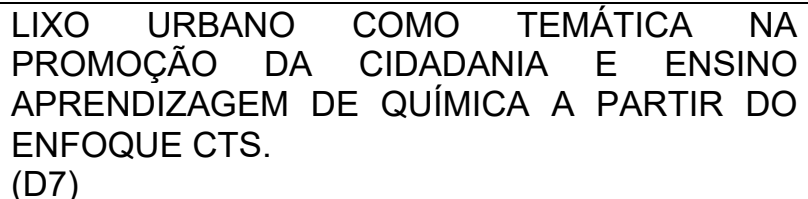 & $\begin{array}{l}\text { BORGES, } \\
\text { Darling } \\
\text { Katiuscia de } \\
\text { Goes. }\end{array}$ & 2017 & UFAM \\
\hline 8 & $\begin{array}{l}\text { O ARTESANATO COMO TEMA GERADOR PARA } \\
\text { O ENSINO DE CIÊNCIAS: UMA PERSPECTIVA } \\
\text { FREIREANA. } \\
\text { (D8) }\end{array}$ & $\begin{array}{l}\text { SILVA, Jaime } \\
\text { Rodrigues da. }\end{array}$ & 2017 & UFS \\
\hline 9 & 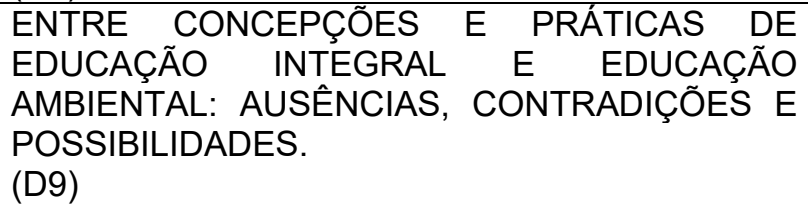 & $\begin{array}{l}\text { ALMEIDA, Lia } \\
\text { Heberlê de. }\end{array}$ & 2017 & UFRGS \\
\hline 10 & $\begin{array}{l}\text { A ABORDAGEM DAS DIMENSÕES CIÊNCIA, } \\
\text { TECNOLOGIA, CULTURA E TRABALHO } \\
\text { DENTRO DO CONTEXTO DO ENSINO MÉDIO } \\
\text { INOVADOR: UM ESTUDO DE CASO. } \\
\text { (D10) }\end{array}$ & $\begin{array}{l}\text { SOUZA, Flávia } \\
\text { Rodrigues de. }\end{array}$ & 2017 & UFSC \\
\hline
\end{tabular}

Fonte: Próprios autores (2019)

\section{Resultados}

A Maioria - 8 das 10 pesquisas analisadas - teve seu desenvolvimento no Ensino Médio regular, apenas uma pesquisa foi desenvolvida no ensino fundamental e uma no Ensino Médio Politécnico. Durante a realização da etapa de unitarização identificamos 41 núcleos de sentido (excertos), emergindo no processo de categorização duas categorias: "Currículos com enfoque CTS no Ensino de Ciências" com 23 Núcleos de sentido; e Pensar crítico de estudantes junto aos objetivos da educação CTS, com 18 núcleos de sentido. Desse modo, trazemos a seguir a comunicação desse novo emergente.

\section{Currículos com enfoque CTS no Ensino de Ciências}

Com a análise do corpus, percebemos que o objetivo da maioria dos trabalhos está voltado à compreensão da perspectiva científico-tecnológica e em quase sua totalidade a compreensão de que existe a necessidade de uma reconfiguração curricular. "Para isso seria necessário reformular e adotar medidas que venham contribuir para a mudança da atual situação, e ainda no desenvolvimento de propostas curriculares que englobem desde a adoção de conteúdos mais relevantes até sugestões de estratégias de ensino e de avaliação [...]" (D7, p. 52). Destacando que a reorganização curricular perpassa pelos objetivos do enfoque CTS, a uma perspectiva democrática, cidadã e contextualizada a "práticas, saberes e tempos, neste processo de modo que a política curricular aspire elevar o desenvolvimento escolar dos estudantes, buscando tornar as propostas educativas mais atrativas dentro e fora do contexto escolar" (D9, p. 27).

O contexto escolar que anteriormente é destacado e denotado em demais pesquisas justamente pelo fato de o currículo denominado tradicional definido a priori, ser encontrado descontextualizado ao cotidiano do estudante, em contrapartida, adentrando aos objetivos do enfoque CTS, em relação aos conteúdos que deveriam compor o novo currículo junto a suas reformulações e 
contextualização ao estudante. Nesse sentido, a pesquisa D5 traz alguns dos contextos que currículos com viés CTS deviam abarcar: "Portanto os conteúdos dos currículos CTS devem evidenciar os contextos mais amplos (social, econômico, político, cultural, ambiental) nos quais se situam a ciência e a tecnologia, e como estas influenciam por sua vez aqueles contextos e vice-versa" (D5, p. 06). Pois, "as propostas curriculares organizadas sobre esta ótica trazem ao contexto escolar questões sociocientíficas, almejando construir princípios para cidadania, justiça social e transformação da sociedade" (D9, p. 60).

Adentrando estes contextos escolares, que influenciam o campo curricular, Auler (2007) defende mudanças profundas em vários contextos, sendo um destes, a abordagem de temas de relevância social que permeiam questões da CT, "[...] configurações curriculares mais sensíveis ao entorno, mais abertas a temas, a problemas contemporâneos marcados pela componente científico-tecnológica" (AULER, 2007, p. 02), enfatizando a necessidade de superação tradicional de currículos pautados pelo ensino disciplinar, regido pela lógica interna das disciplinas. O que é evidenciado por D3, quando menciona que "[...] tendo em vista que o ensino na maioria das escolas brasileiras é desenvolvido de forma descontextualizada e possui como consequência trazer as dificuldades aos discentes no processo de relacionar os conteúdos com o cotidiano". (D3, p. 47).

Neste processo dificultoso em relacionar o contexto de estudantes ao currículo escolar, Paulo Freire ganha grande destaque dentre as dissertações analisadas, pois sua concepção de educação é baseada no diálogo problematizador, com objetivo na formação crítico-reflexiva dos estudantes diante de problematizações das situações pertencentes ao seu mundo vivido, permitindo a esses a compreensão da conjuntura real em que está inserido. Utilizando-se da investigação temática elaborada por ele e sistematizada em sua obra Pedagogia do Oprimido (1987), como forma de se obter temas geradores, com o "esforço de propor aos indivíduos dimensões significativas de sua realidade, cuja análise crítica lhes possibilite reconhecer a interação de suas partes." (FREIRE, 2005, p. 55). Permitindo a autonomia deste indivíduo e uma nova postura diante da construção de seu conhecimento, desenvolvendo-se curricularmente "como uma proposta de ensino que busca enfatizar o contexto dos alunos nas aulas de ciências. Caracteriza-se, por uma reorganização curricular baseada em temas geradores [...]" (D8, p. 54). D4 também enfatiza a reorientação curricular a partir de temas geradores, no caso temas atuais, em que os conteúdos da disciplina de física estejam em função e selecionados a partir do tema, demonstrando a importância da investigação como critério do desenvolvimento destes conteúdos em sala de aula.

[...] a reflexão sobre outras maneiras de refletir a respeito destas organizações curriculares a partir de temáticas focalizando a inserção dos conteúdos mais atuais da física. Nesse sentido ressaltamos que esta investigação se constituiu como um meio pelo qual buscamos explicitar elementos que nos possibilitem pensar em critérios para a seleção e desenvolvimento de conteúdos de física, particularmente aqueles conteúdos contemporâneos (D4, p. 89).

Sendo que os conteúdos contemporâneos destacados anteriormente são temas geradores, provocados a partir de problematizações, ou seja, contraposições advindas de questionamentos e críticas em torno do desenvolvimento científicotecnológico, sendo este o norte para a aproximação do referencial freireano aos pressupostos CTS, que 
[...] podem balizar propostas educacionais para a constituição de uma cultura de participação social, tendo em vista que o movimento CTS, apesar de apresentar-se de forma polissêmica, defende, em linhas gerais, configurações curriculares balizadas por temas, por problemas reais contemporâneos que, devido a sua complexidade, necessitam abordagens de caráter multidisciplinar. Ainda, esse movimento tem como um dos principais objetivos a busca da democratização de processos decisórios sobre temas/problemas contemporâneos, progressivamente condicionados pelo desenvolvimento científico-tecnológico (SANTOS, 2016, p. 66).

Uma forma de contextualizar o currículo envolto a problemas partindo de temas de relevância social, seria a abertura para práticas interdisciplinares dentro do ambiente escolar, o qual, muitas vezes, traz a premissa do ensino pautado tradicionalmente por disciplinas fechadas em que existe a necessidade da "superação de currículos fragmentados sem abordagem com os problemas da vida real (global e local)". (CTS 7, 2017, p. 46). "Em termos de ensino, esse paradigma é oriundo da falácia da organização curricular por disciplinas tradicionais, que gera um acúmulo de informações, mas pouca contribuição para a vida pessoal e profissional". (MOZENA; OSTERMANN, 2014, p. 186). Em contrapartida, introduzo a fala de Souza (2017), que denota a proposta curricular interdisciplinar estar atrelada a questões culturais e cotidianas dentro das disciplinas de componentes curriculares.

A proposta inclui componentes curriculares ligados às questões culturais, ao exercício da leitura, à educação científica e tecnológica, ao esporte e lazer, entre outros. Todos esses componentes são ligados diretamente às áreas do conhecimento, por meio de projetos interdisciplinares (D10, $p$. 25).

Sendo que o foco acaba voltado ao professor, pois participa da elaboração e, consequentemente, das repercussões causadas pelos projetos elaborados em torno de temas CTS, trazendo a participação social de que a renovação curricular necessita, professores fazedores de currículo. Destacamos, também, as palavras de Sacristán (2000), quando se trata de um projeto curricular, integrando diferentes disciplinas, nas quais a interdisciplinaridade exige uma formação diferenciada, não por apenas citá-las como práticas inovadoras, pois podem supor o "novo" dentro do "velho" molde.

A defasagem curricular no ensino de ciências, como é abordada nesta categoria, passa pela ideia de "neutralidade" na qual Ciência-Tecnologia (CT) está entendida como o isolamento dos conceitos em relação ao ambiente em que são gerados, ou seja, a gênese e a produção científico-tecnológica é independente do contexto social, assim evitando que técnicos ou especialistas, os autores que promovem e desenvolvem dela, percebam o interesse de determinados grupos, que podem dar rumos diferentes à inovação (SANTOS, 2012), assim D2 aponta a restruturação para o campo educacional com:

[...] novas propostas curriculares, que tinham como elemento novo a problematização da ciência e da tecnologia, de forma crítica e não neutra, frente aos hábitos, saúde e valores da sociedade moderna. Apontou-se a necessidade de não mais se ensinar uma ciência fechada, de conteúdos prontos e acabados, mas de problematizar a natureza do conhecimento científico, seus processos de produção e suas contradições (p. 24).

Tanto que a falsa ideia de neutralidade pode se aplicar e é claramente demonstrada diante do dimensionamento dado a novas formas de estruturação curricular, abrindo 
novas propostas de elaboração pedagógica e metodologias educacionais, estas pautadas pelo ENEM, que devido sua grande importância em ser uma porta de entrada em universidades e, também, financiamentos estudantis. Ocasionando diversos estudos, quanto a elaboração de conteúdo/temas apresentados em suas avaliações. Tais conteúdos que acabam ditando a estruturação curricular na Educação Básica. Nesse âmbito, entre as dissertações analisadas, buscamos a análise de como estes conteúdo/temas se aproximam do movimento CTS, "aqueles que fazem menção aos problemas reais da sociedade cujas soluções e pela tecnologia". (D6, p. 55). Passam pela ciência com a proposta de conduzir aos participantes do ENEM à Alfabetização e/ou Letramento Científico,

[...] como aspecto central para responder as articulações entre a Ciência, Tecnologia e Sociedade, necessárias para o desenvolvimento integral do cidadão. Embora não seja objetivo do ENEM se propõem a verificar a aprendizagem para a promoção da cidadania que também é objetivo da educação CTS. (D1, p. 36).

Como esta visão de conhecimento encontrado em avaliações do ENEM, com abordagens CTS, expostas pelos autores, induz a sugestão da restruturação de conteúdos no ensino de ciências, principalmente, na Educação Básica, no nível médio, que antecede a avaliação, tanto que D10 que apesar de não enfatizar propriamente o ENEM, mas a estruturação curricular do Ensino Médio regular, destaca a nova proposta de "redesenho curricular baseado em alguns eixos norteadores, almejando alcançar uma abordagem mais crítica e reflexiva". Elaborados, segundo o MEC, em 8 macrocampos nos quais "[..] os projetos de reestruturação curricular possibilitam o desenvolvimento de atividades integradoras que articulam as dimensões do trabalho, ciência, tecnologia e cultura. (D10, p. 33). Fatos que demonstram haver certa influência quanto à reestruturação dos conteúdos. Estas influências curriculares podem suscitar dúvidas, por exemplo, caso a determinação por currículos com maior abrangência de caráter universal, sem vinculação ao contexto e voltados à avaliação do ENEM, venha por indicações governamentais, caímos nas primeiras problemáticas abordadas neste trabalho, quanto à falta de contextualização do ambiente em que o estudante está inserido, movimento de influências que abordamos como de "sentido externo".

Já, o movimento de influências que parte de agentes formuladores dentro do ambiente escolar, sendo os professores importantes neste aspecto, muitas vezes pressionados por pais/responsáveis preocupados com o "futuro de seus filhos", ou como forma de exaltar a instituição escolar que ele se encontra, determinando o conteúdo com o único objetivo, de preparo exclusivo a avaliação do ENEM ou outras avalições externas, como os vestibulares; desse modo, denominamos esse segundo movimento de influências como "interno". O qual pode ser justificado pela importância de uma "boa nota", sendo o principal parâmetro da avaliação e, consequentemente, entrada em universidades. Temos clareza de que as avaliações externas fazem parte do contexto escolar, principalmente no decorrer do Ensino Médio, e, como apresentado em núcleos de sentido anteriores, já existe uma maior preocupação na problematização do próprio conteúdo que envolve a avaliação. Mas, questionamos: todos os estudantes irão prestar esses exames? Todos irão seguir os estudos depois da Educação Básica? Não é importante aprender para a vida, como indica a Lei de Diretrizes e Bases da Educação (LDB)? Afinal, todos recebem o mesmo tratamento. 
Ressaltamos que essa priorização é advinda de uma visão propedêutica na qual o professor transmite aos estudantes algo já pronto, concreto, com o objetivo de adquirirem conhecimentos para utilizá-los no futuro, na vida adulta. Portanto, a teoria antecede a prática, fazendo com que haja uma desvinculação entre a sala de aula e o mundo vivido pelos por eles. Problemática que já tem seu início desde a formação de professores, que imergem em contextos talvez demasiadamente conteudistas com propósito de "dourar a pílula" processo de "cumprir programas", de "vencer conteúdos" (AULER; DALMOLIN; FENALTI, 2009).

No entanto, salientamos que não temos por objetivo descriminar o desenvolvimento de conteúdos entendidos como "duros", principalmente de ciências, mas defendemos a necessidade da problematização dos conhecimentos relacionandoos aos contextos sociais no intuito de uma melhor compreensão desses. Também, defendemos que a elaboração do currículo tenha a participação dos professores pertencentes aquele contexto em que será desenvolvido.

Outrossim, na sequência, abordamos como as pesquisas pertencentes ao corpus de análise abordam a criticidade de estudantes alicerçados nos pressupostos do educador Paulo Freire, a partir de uma educação libertadora, transformadora, na promoção de sujeitos críticos. Essa análise, concomitantemente, considera os referenciais do movimento CTS.

\section{Pensar crítico de estudantes junto aos objetivos da educação CTS}

Grande parte dos trabalhos analisados demonstrava em seus objetivos a busca pelo desenvolvimento do pensamento crítico em estudantes, como demonstrado pelos quatro do total de dezoito núcleos de sentido explicitados a seguir:

\footnotetext{
Colaborar com os estudantes para melhorar o pensamento crítico, o raciocínio lógico, a resolução criativa de problemas e a tomada de decisão; (D5, p. 15).

- Verificar se por meio do uso da fotografia os alunos podem desenvolver capacidade de observação, descrição, e criticidade a partir da temática social educação ambiental. (D9, p. 16).
}

- $\quad$ Opinar criticamente sobre a questão que envolve a problemática do artesanato indígena no estado de alagoas, relacionando os aspectos históricos, sociais e econômicos da atividade; (D8, p. 126).

- $\quad$ Analisar as aprendizagens de conceitos químicos, desenvolvimento da criticidade e responsabilidade social. (D7, p. 58).

$\mathrm{E}$, para a análise, nos valemos dos pressupostos freireanos e referenciais ligados ao movimento CTS; a partir desses, problematizamos qual consciência crítica almejamos que os estudantes alcancem, considerando o corpus de análise.

Os pressupostos educacionais de Paulo Freire são essencialmente dialógicos em contradição à concepção bancária, em que o educador realiza depósitos e os educandos recebem pacientemente, memorizando e reproduzindo. Uma perspectiva que não percebe os homens como seres "vazios" e que o mundo os "encha" de conteúdos, "[...], mas a da problematização dos homens em suas relações com o mundo. (FREIRE, 2005. p. 38). "Diálogo mediado pelo mundo vivido, diálogo entre os conhecimentos do educando e do educador sobre temas/problemas presentes nesse mundo. É o pensar e agir criticamente para intervir com mais qualidade sobre a realidade" (SANTOS, 2016, p. 64).

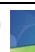


Dessa forma, busca-se uma formação crítica do estudante, que permita ao indivíduo a interpretação dos fatos, fenômenos e processos naturais ou produzidos pelo homem; que promova uma visão de mundo e uma compreensão dinâmica. (D9, 2017, p. 15).

Sendo que, para D7, o primeiro passo para uma formação "de cidadãos críticos e participativos começa com "reflexão" e uma educação voltada para a liberdade e autonomia" (2017, p. 113). Portanto, a educação libertadora e problematizadora de Freire consiste em evidenciar a realidade dos estudantes, para, a partir desta, buscar temas pertinentes e de fato significativos a eles, auxiliando a tomada de decisões e contribuindo na constituição de uma sociedade ética e democrática, que, em grande parte, são objetivos comuns ao enfoque CTS. D10, enfatiza e relaciona a importância da escola como um todo (professores, estudantes, pais), por contribuir na tomada de decisões de estudantes, a partir de uma formação cidadã crítica, humanitária e ética, para o enfrentamento de problemáticas de sua realidade.

\begin{abstract}
A escola precisa, portanto, formar o aluno para uma cidadania crítica, prepará-lo para uma participação social e com formação mais humanitária e ética. O aluno precisa sair da escola sendo capaz de interpretar criticamente e intervir na realidade do mundo em que vive para, assim, transformá-la, e poder lutar por uma justiça social. Para isto, deve-se aprender a ter um espírito de liderança, solucionar problemas e, principalmente, dar o primeiro passo (2017, p. 127).
\end{abstract}

Aproximações entre Freire e CTS balizam propostas em nível educacional para a construção de uma "cultura de participação social", que propõem maior envolvimento em processos decisórios diante de temas sociais que envolvam Ciência-tecnologia (CT), elementos semelhantes aos referencias de Freire, que na superação da "cultura do silêncio" (FREIRE, 1992, p. 20), promovam uma maior percepção de mundo, em que o ser humano deixa de ser objeto histórico e passa a ser sujeito ativo e crítico, problematizando os atuais rumos dados ao desenvolvimento científico-tecnológico e novas sinalizações ao mesmo.

Ponderamos que, a partir de uma educação libertadora, transformadora, promovendo sujeitos críticos, capazes de perceber a sua realidade, a sua condição no mundo (FREIRE, 1987). Junto ao objetivo de educação CTS de "formar cidadãos científica e tecnologicamente alfabetizados capazes de tomar decisões informadas e desenvolver o pensamento crítico e a independência intelectual" (AULER, 2007, p. 1), será possível que eles compreendam sua condição no mundo de forma críticoreflexiva. Tendo em mente que, como nos alerta Freire, ninguém conscientiza ninguém: as pessoas se conscientizam a partir da compreensão da importância de determinada situação em sua vida.

Assim, compreendemos que um diálogo-problematizador das experiências vividas pelos estudantes no contexto escolar, em processos de ensino-aprendizagem, proporciona a problematização e reflexão crítica para tomada de decisões que desenvolva "uma abordagem crítico-social dos conteúdos, ou seja, contextualizar os temas em estudo, compreendendo suas ligações com a prática humana (relações e desigualdades sociais, ciência, tecnologia e meio ambiente)" (D10, p .126). Já, para D8 a contextualização das experiências vividas por estudantes em ambientes escolares também contribui "[...] para promover a valorização das culturas trazidas pelos alunos como forma de colaborar para diminuir, por exemplo, a evasão e o fracasso escolar. Visto que, quando os alunos se encontram no contexto da escola se sentem inseridos e se envolvem nas atividades" (p. 103). 
Pois entendemos que é no ambiente escolar que a alfabetização/letramento científico-tecnológico de fato é promovida na Educação Básica, a qual está "voltada à possibilidade dos indivíduos compreenderem criticamente as relações existentes no mundo atual, principalmente aqueles envolvidos com a dinâmica da ciência e tecnologia e atuarem nesse contexto visando sua transformação". (D4, p. 60). Transformação educacional que tem pretensão de se estender "para além dos muros da escola, promovendo atores sociais comprometidos com uma prática político-pedagógica emancipatória". (D9, p. 58) $\mathrm{Na}$ busca de "favorecer o desenvolvimento e consolidação de atitudes e práticas democráticas nas questões de importância social, que está relacionada com a inovação tecnológica. (D5, p. 18). Para adquirir a consciência crítica que vá além da imparcialidade da simples aceitação sobre questões científico-tecnológicas, que se estabelecem na contemporaneidade, com excludentes sociais, para que estudantes tenham a compreensão de uma educação verdadeiramente crítica. O pensamento críticoreflexivo dos estudantes- que os torne seres com atitude de decisão - necessita ser o objetivo principal a ser conquistado como resultado na Educação Básica, porém:

[...] a deficiência dos mesmos é elevada, sendo que as evidências da relação entre a Ciência estudada nas escolas, suas aplicações tecnológicas e a sociedade são quase imperceptíveis, havendo pouca conexão da educação científica e tecnológica com os impactos gerados na sociedade e em nossas próprias vidas. (D10, p. 14).

Nesta perspectiva, o professor carece tornar-se responsável pela problematização de questões que envolvam a CT junto aos seus estudantes, formando cidadãos capazes de participar na tomada de decisão em sua sociedade, não apenas "comunicando" seus estudantes ou "depositando" conteúdos supostamente neutros, em uma visão de educação "bancária", demonstrando que o pensar crítico não se reporta a simples reprodução e assimilação científico-tecnológica, aos impactos gerados na sociedade e em nossas próprias vidas, mas "é dar um passo mais além das soluções paliativas e enganosas" (FREIRE, 1987, p. 107), surgindo um sujeito emancipado participativo capaz de intervir em seu contexto. Apesar da precariedade escolar ser uma realidade dura e pouco convidativa a professores, em meio a barbáries que acometem, atualmente, a educação brasileira, como, por exemplo, o investimento cada vez menor e a desvalorização crescente do profissional da educação.

\section{Considerações}

$\mathrm{Na}$ presente pesquisa, que se limitou a identificar como os diferentes vieses de currículo com enfoque CTS estão sendo abordados na Educação Básica, dentro do objetivo do presente trabalho - aproximações aos pressupostos do educador Paulo Freire a referenciais ligados ao movimento CTS - identificamos poucas pesquisas para composição do corpus de análise, e em seu total somente dissertações, em grande parte, pesquisas desenvolvidas em nível médio, apenas uma em nível fundamental final, e que de fato consideram a necessidade de reconfiguração do currículo vigente definido a priori, de organização disciplinar sem conexão com a realidade, com temáticas e a partir delas maior ênfase a conteúdos significativos aos estudantes e de como a CT influencia tais contextos e é influenciada por eles, perpassando diferentes disciplinas no ensino de ciências. 
A crítica deste trabalho, em parte, perpassa a implementação da nova Base Nacional Comum Curricular (BNCC), que a partir do ano 2020 deve nortear os currículos dos sistemas e redes de ensino da Educação Básica em todo o Brasil. Apesar de alguns trabalhos analisados, pelo ano de suas pesquisas, não discutirem em si a nova BNCC, a ocorrência de reformulações já era suscitada na BNCC ainda vigente, porém a discussão continua na nova Base, principalmente ao levarmos em conta o fato de um currículo "fechado e normativo" como propriamente se declara e explicita em sua nova BNCC "[...] um documento de caráter normativo que define o conjunto orgânico e progressivo de aprendizagens essenciais que todos os alunos devem desenvolver [...]" BRASIL, 2019). Criando a percepção de generalidade sobre professores e estudantes, pois os tratam de igual forma, negando sua individualidade, suas diferenças, impondo conteúdos que julgam serem necessários ao desenvolvimento do estudante, garantindo um patamar comum a todos. Forma aqui vista como negligente nos múltiplos contextos de um país continental e diverso como o Brasil, assim estabelecendo poucas conexões entre currículo e realidade, como discorrido anteriormente, conexões que necessitam perpassar diretamente as configurações da nova BNCC, pois é ela que passa a ser referência nacional para a formulação dos currículos dos sistemas e das redes escolares.

Com a análise desenvolvida neste trabalho, buscamos contribuir para que haja mais problematizações críticas a respeito de currículos, que se produzam configurações curriculares que visem à compreensão da relações CTS na Educação Básica, uma reorganização curricular que perpasse pelos objetivos do enfoque CTS, que tais configurações sejam mais sensíveis ao entorno em que o ambiente escolar se encontra, mais abertas a temas, a problemas contemporâneos marcados pela componente científico-tecnológica, resultados que já se mostram evidentes na avaliação do ENEM, tendo maior preocupação em corresponder a estas demandas. Porém cabe ressaltar a preocupação por parte dos professores em não tornar a avaliação em prioridade única de visão propedêutica fazendo com que haja uma desvinculação entre a sala de aula e o mundo vivido pelos estudantes, que vai contra aos objetivos CTS e a perspectiva freireana de educação, suscitando a questão do preparo da avaliação do ENEM quanto à abrangência de questões sociocientíficas mais próximas da realidade vivida.

Com isso, também, uma procura por tomadas de decisão junto a um olhar crítico, que é destaque nas pesquisas analisadas e, além disso, alicerçados nos pressupostos de Freire (2005), desde questões metodológicas de desenvolvimento de trabalhos, como a busca do tema gerador através da investigação temática com o objetivo de enfocar o mundo vivido, para, a partir de uma educação libertadora, transformadora, que promova criticidade, sujeitos capazes de perceber e interferir na sua realidade, a sua condição no mundo.

O que nos suscitou novas questões de análise, agora com o olhar voltado para as configurações curriculares diante de propostas a serem trabalhadas em sala de aula, visando à complementariedade destas duas etapas: configurações curriculares e posterior prática em sala de aula. Assim, a prática de sala de aula se estabeleceu como problemática de investigação e, ao final, como objetivo para reestruturar o currículo tido como tradicional. Quais metodologias são usadas para investigar o resultado adquirido pelo estudante após a prática em sala, buscando elucidações diante das relações científico-tecnológicas no ensino de ciências? Com pretensão futura, dar continuidade à pesquisa e maximizar a compreensão da forma que configurações curriculares estão sendo desenvolvidas na perspectiva da

L


abordagem por temas na Educação Básica, pois como identificamos nesse trabalho a existência da necessidade de reconfiguração curricular e esta, perpassando pela inserção de temas, buscando aproximações a perspectiva Freire/CTS no desenvolvimento destes. A nova BNCC, apesar de recentemente propor reformulações, não estabelece proximidades com a realidade de professores e estudantes, em sua prática, e continua sendo algo muito geral, fato que sustenta a compreensão de incompatibilidade com um currículo de caráter universal, como acaba se apresentando, carecendo de uma maior regionalização, considerando o mundo de quem vive esse currículo.

\section{Referências}

AULER, Décio. Enfoque Ciência-Tecnologia-Sociedade: Pressupostos para o contexto brasileiro. Ciência e Ensino, v.1, n. especial, p. 1-20, 2007.

AULER, Décio. DALMOLIN, Antonio Marcos Teixeira. FENALTI, Veridiana dos Santos. Abordagem Temática: natureza dos temas em Freire e no enfoque CTS. Alexandria, Florianópolis, Santa Catarina, v. 2, n. 1, p.67-84, 2009.

FREIRE, Paulo. Pedagogia do Oprimido. 48 Ed. Rio de Janeiro - RJ: Paz e Terra, 2005.

FREIRE, Paulo. Pedagogia da Esperança: Um Reencontro com a Pedagogia do Oprimido. Rio de Janeiro: Paz e Terra, 1992.

MOZENA, Erika Regina. OSTERMANN, Fernanda. Uma revisão bibliográfica sobre a interdisciplinaridade no ensino das ciências da natureza. Ensaio, Belo Horizonte, v. 16, n. 02, p.185-206, 2014.

MORAES, Roque. Uma tempestade de luz: a compreensão possibilitada pela análise textual discursiva. Ciência \& Educação, Bauru, v.9, n.2, p.191-211, 2003.

MORAES, Roque. GALIAZZI, Maria do. Carmo. Análise Textual Discursiva de Múltiplas Faces. Ciência \& Educação, v. 12, n. 1, 2006.

SACRISTÁN, J. Gimeno. O currículo: uma reflexão sobre a prática. 3. Ed. Porto Alegre: Artmed, 2000.

SANTOS, Rosemar Ayres dos. A não neutralidade na perspectiva educacional ciência-tecnologia-sociedade. Dissertação (Mestrado) - Curso de Pós-Graduação em Educação, Universidade Federal de Santa Maria, Santa Maria, 2012.

SANTOS, Rosemar Ayres dos. Busca de uma participação social para além da avaliação de impactos da ciência-tecnologia na sociedade: sinalizações de práticas educativas CTS. Tese (Doutorado) - Curso de Programa de Pósgraduação em Educação, Universidade Federal de Santa Maria, Santa Maria, Rs, 2016. 
Recebido: $26 / 12 / 19$

Aprovado: $24 / 04 / 20$

Como citar: SCHWAN, G.; SANTOS, R. A. Dimensionamentos curriculares de enfoque CTS no ensino de ciências na educação básica. Revista de Estudos e Pesquisa sobre Ensino

Tecnológico (EDUCITEC), v. 6, e098120, 2020.

Direito autoral: Este artigo está licenciado sob os termos da Licença Creative CommonsAtribuição 4.0 Internacional.

(c) (1) 